\title{
에티오피아 식수개발 사업 사후평가
}

김 재 곤 / 한국지질자원연구원 환경재해연구실장

\section{I . 배경 및 필요성}

2004년부터 시작된 극심한 가뭄으로 동부아프리카 지 여 (케냐, 에터오피아. 말라위, 잖비아, 모잔비크 등)의 주민들은 문론 가축들까지 아사 위기로 40년 만에 최 악의 기뭄 피해를 걲고 있다. 특히, 가뭄 피해가 상습 적으로 반복되고 있는 에티오피아 남부 지역은 강우량 이 적고, 지형 지질 득성상 지표수 자원의 활용도가 극 히 제한되어 있음에 따라, 지역 주민들의 심각한 용수 문제의 해걸을 위해서는 지하수게발이 가장 효과적일 뿐만 아니라 시급히 이루어저야 할 것으로 판단된다. 이에 시하수 임물 개발 및 개보수를 통해서 시원 후 즉 각적인 식수이용인구 확대효과를 볼 수 있을 것으로 기대된다. 아울러, 식수시선까지의 접근성이 매우 떤 어저 수십 $\mathrm{km}$ 를 도보로 이동하여야 식수를 공급받을 수 있는 실정인 바, 금번 사업을 통해 대상시역의 식수 접근성이 대폭 개선될 것으로 판단되녀, 이에 따라 잖 재된 노동력의 횔용이 가능할 것으로 기대된다.
II . 사업개요

\section{1. 사업대상 지역 현황}

\section{가. 지하수 자원 개황}

사하라이남 아프리카지역의 대부분(약 $40 \%$ )은 기반암 이 고대의 결정질 압석으로 구성되어 있어, 지하수 산 출량은 비교적 낮으나 대수층이 넓게 분포되어 있는 특성을 가지고 있다. 이리한 암석은 투수성이 낮고 층 의 두께도 얇아 결과적으로 투수량계수가 작게 나타나 며, 특별한 시질 구조가 나타나시 않는 한 시하수의 산 출을 기대하기 어려운 것이 일반적이다. 그러나 다행 스럽 게도 아프리카 지역의 기반암을 구성하고 있는 결 정질 암석들은 일반적으로 약 $10 \sim 30 \mathrm{~m}$ 두께의 풍화대 를 가시고 있어, Guji 시역의 수백만에 달하는 농촌시 역 주민들에게물을 공급하고 있는 않반대수층을 구성 하고 있다. 이 지역의 지하수 대수층 특성상 지하수 관 
정의 신출랑은 $10 \sim 15 \mathrm{~m}^{3}$ 일 정도로 낮은 편이고 지하 수를 이용할 수 있는 시설의 숫자가 매우 적기 때문에 대부분 장기적인 관점에서 함양량은 시하수 이용량을 충분히 감당할 수 있는 수준인 것으로 평가되고 있다. 따라시 가뭄에도 지속적으로 이용이 가능한 지하수 시 설을 확보하기 위해서는 지역의 특성이 충분히 감안된 시하수 관정을 설계하여 설치하는 것은 물론, 적절한 유지관러 대책이 수립 되어야만 할 것이다.

\section{나. 지하수 개발 현황}

에티오피아 수자원 관리 및 개발계획은 정부의 수자원 부가 총길하고 있다. 동력자원부(Ministry of Mines and Fnergy)에서는 지하수 기발 분야의 업무를 관장 하고 있으나, 지하수 분야의 예산이 충분치 못하여 적 극적으로 사업을 추진하지는 못하고 있으녀 주로 광산 개빌에 중점을 두고 있다고 한다. 지하수 시공업체는 대부분 수도인 아디스아바바에 집중되이 있으며 약 50 - 60개 업체가 활동 중인 것으로 파악되고 있다. 조 사 기간 중에는 암반 시하수 개발이 가능한 장비를 $3 \sim 4$ 대 정도 목격할 수 있었으며 장비의 규모를 보아 약 $100 \sim 200 \mathrm{~m}$ 심도의 시공이 가능한 장비들로 판딘된 다. 에터오피아 내에서도 지속적으로 암반관정이 기발 되어 온 것과 관련 공무원들의 의견을 참작할 때 암반 관정의 시공 능럭은 확보되어 있는 것으로 생각되나. 시공업체 중에서 대외적인 신뢰도를 갖고 있으면서 적 정수의 장비와 기술진이 확보되어 있는 업체는 5 기 내 외 업체일 것으로 판단된다. 아디스아바바로부터 남쪽 으로 약 $774 \mathrm{~km}$ 거리에 위치한 Moyale시 지역 인근에 태양열을 이용한 지하수 시설을 시찰해본 바, 이 관징
은 현재 약 $50 \mathrm{~m}^{3} /$ 일 내외의 앙수랑을 보이고 있었으 나, 현지 관계자에 따르면 현재는 가뭄으로 인해 양수 량이 약 $60 \%$ 까시 감소된 상태로 해마다 양수량이 감 소되고 있는 실징이라고 한다.

\section{2. 사업추진 기본 방향}

「2006 2008 동아프리카 식수개발 지원계획」의 단계 변 지원의 인환으루 즉각적인 식수이용인구 확대효과 를 볼 수 있는 지하수게발 및 기보수사업을 식수환경 이 얼악한 시골시역에 어선 츠진하도록 하었다. 탐사 후 성공의 확률이 높지 않은 전을 감안하여 숙련된 기 술자를 파견, 공사 관리감독을 위탁하여 기한 내 사업 이 완료하도록 하였으며 향후, 2007 2008년간 후속 적인 지원을 고려, 파견된 전문가를 통해 현지 지질현 황, 정부정책 및 타 국제기구 지원동향 파아, 우량사업 빌굴 등의 임무를 부여하였다. 그리고 사업규모가 소 규모이며 케냐 우물개발사업과 동시에 추진되는 사업 임을 고려하여 단일기관(업체)에 2국 2건의 사업(에티 오피아 및 케냐)을 일괄 위탁하여 사업춪진의 효율성 을 제고하였다.

\section{3. 사업 내용 (표 1)}

\section{4. 평가 방법}

첫째, 본사업과 관련된 타당성 김토 및 조사, 실시조사, 실행계회, 진행보고, 수행졀과보고, 사업종료평가, 설 문지 답변 자료 등을 검토하여 서류평가를 실시하였다. 둘째, 에티오피아 징부 수자원부(Department of 
〈표 1) 평가대상 사업개요

\begin{tabular}{|c|c|c|c|}
\hline \multicolumn{2}{|c|}{ 구 분 } & \multicolumn{2}{|c|}{ 내 용 } \\
\hline \multirow{2}{*}{ 사업명 } & 국문 & \multicolumn{2}{|c|}{ 에티오피아 Borena 또는 Gujij지역 우물개발사업 } \\
\hline & 영문 & \multicolumn{2}{|c|}{ The Project for the Devebprnert of Gound Water in Borene or Guji zone of Orniya Region in Ehiopia } \\
\hline \multicolumn{2}{|c|}{ 사업목적 } & \multicolumn{2}{|c|}{$\begin{array}{l}\text { 가뭄으로 식수부족이 심각한 지멱에 지하수 우물을 개발함으로써 주민들의 식수 접근성을 제고, 식수 이용가능민 } \\
\text { 구 약 } 10,000 \text { 명 증가 기대 }\end{array}$} \\
\hline \multirow{4}{*}{ 사업 } & \multirow{3}{*}{ 아국 } & 우물 개발 & $\begin{array}{l}\text { - Guji지역 신규우물 3개공' 공: 디젤, 2공:핸드펌프) } \\
\text { - 탐사. 굴착, 이용시설 설치 등 }\end{array}$ \\
\hline & & 기자재 공여 & - 디젤펌프, 물탬크, 철감배관, 콘크리드 관수로 등 \\
\hline & & 공사괸리 전문가파견 & $\begin{array}{l}\text { - 공사관리 전문가 파견(2인 1조, 총 } 5 \mathrm{MM}) \\
\text {-현지시공업체 선정, 공사감독, 향후 지원사업 발굴 }\end{array}$ \\
\hline & 수원국 & \multicolumn{2}{|c|}{ - 각종 인허가, 면세 통관, 사무공간 제공 등 햄정적 지원 } \\
\hline \multicolumn{2}{|c|}{ 사업대상지멱 } & \multicolumn{2}{|c|}{ - Oromia주 Guji (수도 아디스아바바에서 낟동쪽으로 $620 \mathrm{~km}$ 지점) } \\
\hline \multicolumn{2}{|c|}{ 사업기간 /규모 } & \multicolumn{2}{|l|}{-2006(†년)/25만불 } \\
\hline \multicolumn{2}{|c|}{ 수혜자 } & \multicolumn{2}{|c|}{ - 사업대상지역 인근 주민 약 10,000 명 } \\
\hline \multirow{2}{*}{$\begin{array}{l}\text { 기대 } \\
\text { 효과 }\end{array}$} & 아국 & \multicolumn{2}{|c|}{$\begin{array}{l}\text { - 아프리카지역에 대한 인도적 지원을 동해 대외적 국가이미지 제고 } \\
\text { - 에티오피아외의 우호적 협력관계 강화 }\end{array}$} \\
\hline & 수원국 & \multicolumn{2}{|c|}{ - 깨끗한 식수이용인구 약 - 0,000 명 증가 기대 } \\
\hline \multirow{2}{*}{$\begin{array}{l}\text { 사업시행 } \\
\text { 기관 }\end{array}$} & 아국 & \multicolumn{2}{|c|}{ 한국국제협력 단(KOCA) } \\
\hline & 수원국 & \multicolumn{2}{|c|}{ 수지원부(Vinistry of Water Resources) } \\
\hline \multicolumn{2}{|c|}{ 상위프로그램 } & \multicolumn{2}{|l|}{ 안전한 식수개발 } \\
\hline
\end{tabular}

Water Resources) 수자원정책과 대외협력국강 및 여 너 실무사와의 면담을 통하여 에티오피아 식수공급현 황 및 정책, 식수난 해걸을 위한 외부지원 현황, $\mathrm{KOICA}$ 식수개발사업의 효과와 에티 오피아 정부의 수 자원정책과의 연계성 등을 검토하였다. 그리고 Guji지 역 수자원책임자, 시설운 용책임자, $\mathrm{KOICA}$ 에터오피 아사무소 소장 및 직원, 한국농촌공사 현장파견사업단 장의 면담을 실시하여 사업형성 및 수행과징, 에티오 피아의 지원, 사업의 효과, 시설운용, 사후관리 등을 검토하였다. 셋째, 않반관정 1개소를 개발하여 지역주
민에게 식수를 공급 중인 Gujji지역을 방문하여 시설설 치현황, 채수현황, 시설유시관리현황, 식수분배현황 등을 조사하였다. 식수사용 지옂주민들의 면담을 통하 여 시설운영실태, 시설에 대한 민족도, 문제점 및 긴의 사항 등을 표악하였다. 마지막으로 Guji 지역 수자원 관리 공무원, 식수개발시설 관리자, 개발식수 활용 지 역주민을 대상으로 사업 시기, 규모, 효과, 만족도, 문 제짐, 건의사항에 대한 설문조사를 실시하고 조사결과 의 분석을 통하여 사업의 효율성을 검토하였다. 


\section{III. 평가 결과}

\section{1. 타당성}

\section{가. 수원국의 수요 및 관련정책과의 연관성}

에터오피아 정부는 신경제게발계획(Plan for Accelerated and Sustained Development: 2005/6 2009/10)을 수립하여 시행하고 있으녀 물 부 족문제 해결이 국가빌전목표 달성의 핵심요소로 인식 하여 용수확보를 국가우선정책으로 선정하여 시행하 고 있다. 수원국인 에티오피아는 식수의 적정 수질과 수량 공급비율이 $50 \%$ 이하인 국가이며 아프리카에서 식수의 수질과 수량 확보문제가 가장 심각한 나라로서 깨끗한적정량의 식수공급이 시급하다.

사업대상시역인 Guji시역은 세계기후변화의 영향으로 최근 3 년간 연평 균 강수량이 $500 \mathrm{~mm}$ 에 서 $300 \mathrm{~mm}$ 로 감소 하였으며 강수부족에 의하여 야기 되는 문제에 대한 대 치능력이 부족한 정부 및 지역주민은 용수부족문제에 적절히 대처하고 있지 못하고 있으며 외부의 지원이 절실하다.

에티오피아 남부지역은 물 획보문제로 종족분쟁이 빈 번히 발생되고 있으며, 특히 사업 대상지역인 Guji지역 은 물 비족으로 가축을 포함한 시역주민 1가족의 1 일 식수 및 생활용수 사용량이 $20 \mathrm{~L}$ 이며 물 확보는 지역 주민의 생존과 직결되고 있는 지역이다. 따라서 Guji 지역에서 지하수 개발을 통한 식수공급 사업은 사업대 상시역의 강수량이 비족한 자연특성, 시역주민의 수
요, 수원국 정부의 수자원확보정칙과 부합되는 적절한 사업으로 판단된다.

\section{나. 우리나라의 대외 원조정책과 부합성}

우리나라는 2000 년 UN총회에서 발표한 MDGs 달성 을 위한 국제원조사업을 확대하고 있으며 KOICA는 우러나라가 상대적으로 비고우위에 있는 7개 분야를 선정하여 중점적으로 지원하고 있다. 지하수 개발을 통한 식수공급 사업은 $\mathrm{KOICA}$ 의 7 기 중점지원 분야 중 하나인 보건의료분양의 Goal 4(안전한 식수공급확대) 에 해당되는 사업이다. 뜨한 본 사업은 $\mathrm{KOICA}$ 의 사업 추진목표 뿐만 아니라, 주요 추진방향인 수원국의 필 요 및 정책에 부합된 지원과 우리니라의 게발겅험의 전수에 부합된다

\section{다. 국제사회의 지원방향과 부합성}

식수개발사업은 UN이 2015 년까지 달성을 목표로 하 는 MDGs의 goal 7(시속가능한 환경 보장 중 안전한 식수 확보)에 해당된다. 그리고 $\mathrm{EU}$ 국가, 미국, 일본 등 선진국에시 인전한 식수공급을 위해 지표수 이용 을 위한 댐건설, 정수장 설치 및 운형, 식수공급시설 건설 및 운영, 수자원개발기술과 시설의 유시관리 교 육 등을 동하여 에터오피아를 비롯한 아프리카에 내 한 지원횔동을 수행하고 있다. 또한 본 식수개반사업 은 동아프리카 식수문제 해결을 위한 국제사회의 노 력에 부합된다.

\section{라. 사업계획수립의 적절성}


시업대상지역인 Guji지역은 만성적인 물 부족을 겪고 있는 지역으로 사업의 효과를 극대화할 수 있을 것으 로 판단된다. Guji시역의 시질은 결정질 암석으로 구성 되어 있으며 적은 강우량으로 인하여 지하수 수량이 적 어 지하수 개발사업은 신패할 확률이 높을 것으로 판딘 되었다. 이에 지하수 개발사업의 1단계로 지질조사, 물 리탐사, 굴착위치 선정은 기술력이 상대적으로 높은 움 리 기술진에 의해 선행되고, 2 단계로 굴착 및 시설설치 는 현지 전문업체를 통하여 수행되어야 성공확률을 높 일 수 있다. 사업수행 결과 지역주민 1만 명을 대상으 로 식수를 공급할 목적으로 암반관정 2개소 개발이 계 획되었으녀 목표대비 계획이 적절히 수립되었다고 판 단된다.

\section{2. 효과성}

\section{가. 사업 목표의 달성도 평가}

우물 개발사업의 목적인 지역주낀에게 깨끗한 식수를 제공함으로서 수인성 전염병 예방에 크게 기여한 것으 로 판단된다. 그리고 어린이와 부녀자들이 식수를 긷 는데 빈나전 이상 소오되었으나 사업완류 후 지역주민 의 식수확보 시간은 평균 1 시간 30 분으로 감소되어 식 수확보에 소요되는 노동력 비담이 경감되었으며, 이는 유휴 노동럭의 경제활동으로 지여경제 발전에 기여하 고 있다.

\section{나. 사업 활동의 목표활동 기여도 평가}

당초 2 개소 관징개빌을 계획하였으나 3 개소에서 관징
기발을 시도하여 1 기소는 디젤발전기를 사용하여 식 수를 공급하고 있으머 2개소는 핸드펌프를 이용하여 식수를 공급하고 있다. 사업대상지인 Guji시역의 시 질과 적은 강수틍성으로 지하수 개발사업의 성공확률 이 낮은 지역임을 고려할 경우 성공적으로 사업이 수 행되었다. 기자재의 적절한 공급, 유지관리 매뉴얼의 전수 등을 통하여 향후 시역주민의 안전한 식수공급 과 시설의 지속성에 기여할 것으로 판단된다.

\section{다. 사업의 target group(수원국, 수혜기관, 사회)에 대한 기여도 평가}

사업대상지역인 Guji지역의 수자원 담당부서는 $\mathrm{KOICA}$ 의 식수기발사업을 통하여 전수받은 기술력을 활용하여 향후 유사사업을 자체사업으로 수행할 계획 을 가지고 있어 본 사업을 통한 기술전수는 수원국의 식수공급 능력향상에 기여하였다고 판단된다.

만성적인 식수난을 겪고 있는 Guji지역 주낀 1만 명에 게 깨끗하고 안전한 식수를 공급함으로서 수인성 전염 병 예방에 크게 기여하고 식수확보를 위해 소요되는 노동력 투입이 경감됨으로서 목축, 농경 등 다른 생산 활동에 노동력을 집중하여 주민소득향상과 지역경제 발전에 기여하고 있다.

\section{3. 효율성}

\section{가. 사업의 비용 효율성 평가}

제한된 예산범위 내에서 에티오피아 표군단가를 기준 
〈표 2〉사업 예산 배분

\begin{tabular}{|c|c|c|}
\hline 구븐 & 게획금액(천US\$) & 주요 수행사항 \\
\hline 우물개발 및 장비지원 & 140 & $\begin{array}{l}\text { 탐사, 굴착, 우물청소, 기자재!디젤발전기, 수중펌프, 배관 } \\
\text { 저장탬크, 기타 시설물)지원 }\end{array}$ \\
\hline 전문가 파견 & 80 & 공정관리 및 감독 \\
\hline 예비비 & 30 & \\
\hline
\end{tabular}

으로 항목별로 적절하게 배분되었다. 관정굴착공정 진행 중에 목표수량 확보가 어러울 경우 핸드핌프로 대체하고 굴칙지점의 재선정과 굴칙 등 돌발 상황에 신속히 대처함으로서 에산을 절감하였다.

\section{나. 사업의 산출물 달성정도 및 완성도 평가}

당초계획은 2게 관정을 굴착하고 태양열 발전기를 이 용한 양수 및 급수시설을 설치하는 것으로 되어있으 나, 수량확보와 태양열발전기의 양수능력 문제로 3 개 관정을 굴착하고 2 개 관정은 핸드 펌프를 이용한 양수, 1 게 관정은 디젤발전기를 이용한 앙수로 전환되었다. 당초 목표인 지역주민 1만 명에게 깨끗한 식수공급은 2 개 핸드펀프 관정과 1 개 디젤발전기 관정으로 충분히 달성되었으며 사업지역의 지질과 지하수 부존량을 고 려한 적절한 계획변경으로 판단된다.

관정굴착과 비대시설 설치완료 후 적절한 운용설명서 를 지역주민과 수자원 관리부서에 제공하였으며 시설 운용에 횔용되고 있다.

\section{다. 사업실시 기법의 유용성 평가}

현지의 사정을 잘 아는 지하수개발 현지 전문 업체를 입찰을 통하여 신정하고, 시공을 위탁함으로서, 현지 에서 발생될 수 있는 돌발 상황에 효율적으로 대처하 고 사업의 효율성을 증가시켰다. 그리고 탐사, 굴착위 치선정, 관정굴착, 관정자재 설치, 배관 및 급수대 설 치로 이어지는 일련의 작업과정은 지하수개빌사업의 표준과정으로서 적전히 수행되었다. 뜨한 지질과 적은 강수특성으로 지하수 기발사업의 실패확률이 높은 것 을 대비하여 예비비 및 사업 관리비 활용계획은 적절 하다고 판단된다.

\section{라. 사업 관리 체계의 효율성 평가}

사업 대상지여은 KOICA 사무소와 연방정부가 위치한 아디스아바바와 원거리 $(750 \mathrm{~km})$ 에 위치하고 있어 통신 과 교통시설의 후진성으로 원활한 의사소통이 어려웠 으며 이는 사업진행의 장해요인으로 작용하였다. 그리 고 강비 및 인력투입 지연, 종족분쟁, 연료판매 중단, 인허가 지연으로 사업수행이 지연되었으며 예산부졷 으로 파견 전문가의 조기귀국과 원거리 현장관리가 발 생되었다. 이러한 문제는 사전조사 및 검토 기간이 짧 아서 사업수행과정에서 발생될 수 있는 리스크 분석이 
충분하지 못하여 발생한 것으로 판단된다. 이에 사업 시행기관인 한국농촌공사가 직접 수혜기관인 지방정 비와 협의하여 사업을 진행한 점은 적절하였다. 향후 유사사업의 수행 시에는 충분한 시간을 가지고 면밀한 리스크 분석을 신시하고 사업 계획에 반영 되어야할 것 이다.

\section{4. 파급효과}

\section{가. 사업의 상위목표(Overall goal)달성 가능 성 및 긍정적 효과}

상위목표인 '수혜주민에게 깨끗하고 안전한 식수공 급'을 달성하였으며 또한 UNN의 MDGs 및 KOICA의 중점 추진분야와부합된다.

\section{나. 사업의 역량개발 및 제도강화 기여도 평가}

식수개발사업으로 지역주낀에게 1 일 50 톤의 식수를
공급하고 있으며 식수공급을 계기로 주민들의 걸속력 이 강화되었고 추가적인 생활용수의 확보를 위하여 주 민차체사업으로 소규모 서수시 조성을 시작하는 등 시 역발전에 긍정적으로 기여하고 있다. 그리고 $\mathrm{KOICA}$ 의 식수개발을 계기로 지역정부 · 수자원 관계자들은 지하수 개발사업에서 지질조사 및 물리탐사가 중요한 비분을 차시하는 것을 인식하였으며 향후 유사사업을 지여정부 자체사업으로 추진할 예정이다. 그러나 시수 개발사업을 통하여 지역사회 발전과 수헤기관의 역량 강화에 큰 영향을 주었지만, 식수기발사업에 대한 체 계적인 교-육이 수반되었다면 사업의 효과를 극대화 할 수 있을 것으로 판단된다.

\section{5 . 지속가능성}

\section{가. 수혜자(수원기관, 사회)의 시설, 장비관리 및 유지 가능성 평가}

식수관정의 는거리 수혜자를 중심으로 주민자치운영

〈표 3) Guji 지역 주민의 수혜사례

\begin{tabular}{|c|c|}
\hline 구 분 & 사 례 \\
\hline 보건위샘 & $\begin{array}{l}\text { - 오염 지표수의 식수이용 사례가 없어짐 } \\
\text { - 물 부족으로 출산 후 임산부가 씻지 못하였으나, 사업 이후에 깨끗한 물의 확보로 첨결유지 및 임산부의 보건 위생이 } \\
\text { 개선되었음 }\end{array}$ \\
\hline 노동력 경감 & $\begin{array}{l}\text { - 식수확보에반나절에서 하루 정도 소요되었으나 사업 이후 평균 } 1 \text { 시간 반 정도로 감소되었음 } \\
\text { - 물 확보를 위하여 가축과 함께 원거리 이동을 계속하였으나. 현재는 깨끗하고 안전한 물의 확보로 우물을 중심으로 } \\
\text { 정착샘활이 가능하며 이동에 따른 노동력이경감되었음 }\end{array}$ \\
\hline 삼 산 할동 & $\begin{array}{l}\text { - 물 길러오기에 소요되는 노동력의 경감 및 점착생할로 인하여 목축과 농겸의 병행이 가능해젔으며 유휴노동력을 이용 } \\
\text { 하여 밀. 보리 등 겸작활동을 하고 있음 }\end{array}$ \\
\hline
\end{tabular}


위원회를 구성하여 관정의 관리, 채수랑, 채수시간 등 에 대한 규정을 정하고 자치적으로 운영하고 있다. 그 더나 지역주민, 수혜기관은 낮은 장비수리능력과 기술 인력의 부종으로 사소한 고장에도 자체기술력으로 대 처하지 못하고 있으며, 고장 시에 필요한 물품의 지역 조달이 어려워 원거리 전문 업체에 의뢰하여 문제를 해결하고 있는 실정으로 고장에 대하여 신속하게 대처 하기가 어렵다. 이러한 현상은 에터오피아 농촌지역의 일반적인 현상이며 체계적인 유지 보수 교육 등은 향후 해결해야 할 문제로 판단된다.

\section{나. 사업의 자립발전성 평가}

수혜주민은 식수기발시업의 효과(깨끗하고 안전한 식 수확보, 수인성 전염병 에방, 식수획보를 위한 노동력 의 경감, 지여경제발전에 내한 기여)에 내한 중요성을 인식하고 있으며, 이를 생산 활동과 연계시키기 위한 노력을 하고 있다. 그리고 수헤기관인 Guji지역 수자 원 관리부서에서는 $\mathrm{KOICA}$ 의 식수개발사업 이후, $\mathrm{KOICA}$ 시원사업과 유사한 사업을 계획하고 있으며 자체개발사업을 위한 노력을 하고 있다. 그러나 수혜 기관인 지방정부의 행정시스템의 낙후, 주인정신 (ownership) 결여 등으로 체계적인 행정지원이 어려 워 자립발전에 장애가 될 이러가있다.

\section{6. 기타}

\section{가. 사업의 현재 상황 평가}

식수개발사업의 일환으로 시행된 핸드핌프관징 2개소
와 디젤발전기관정 1게소는 지역주민에게 안전한 식 수공급을 원활히 수행하고 있으며 지역발전에 크게 기 여하고 있다. 그너나 지하수관정으로부터 양수를 위한 설비는 일정기간이 경과함에 따라 소모성 부품의 수명 소진으로 인하여 고장이 반생 되며 지역주민 및 수혜기 관인 지방정부의 대처능력 부족으로 지속가능성이 저 해될 우려가 상존하고 있다. 이에 시역주민은 디젤발 전기 연료비용 부답의 어려움을 호소하고 있으녀 연료 비용의 부족으로 식수공급기능이 원횔히 수행되지 못 할 게연성이 있다. 지방정부 관계자 및 지역주민에 따 르면 디젤발전기관정은 양수량이 감소되고 있으며 현 재는 지여주민의 수요량에 부응하나 향후 지속적인 양 수로 인하여 지하수 고갈로 식수공급능력이 저하될 우 려가 있다. 그리고 지하수 앙수량 감소는 사업대상지 역인 Guji지역의 지질과 부족한 강수량에 기인한 낮은 지하수 함량에 원인이 있으녀 지여주민과 지방정부 관 리자의 인식부족으로 과다양수와 이에 수반된 지하수 고간문제가 반생될 수 있다. 이는 지하수 고간에 의한 관정 기능상실 방지는 적정 양수량을 결정하여 양수시 간과 양수량의 조절로 가능하다고 판단된다.

\section{나. 타 국제사회 지원사업과 중복성 평가}

미국, $\mathrm{EU}$ 국가, 일본, 중국, $\mathrm{UN}, \mathrm{NGO}$ 등 다양한 국가 와 단체에서 시수개발사업을 에터오피아 여러 지역에 시 유상 혹은 무상으로 지원하고 있으나, 식수난이 심 각한 Guji지역에서는 유사사업이 없었다. 그리고 외국 에 의하여 지원되는 대부분의 사업은 지하수개발 혹은 지표수개발 사업으로 구성되어 있으녀 Guji지여과 같 이 식수문제가 심각하고 지하수 부존량이 직은 지역에 
서 식수공급시업은 지하수게발과 지표수기발이 융합 된 형태의 식수공급이 공급수량 확보에 유리하다고 판 난된다.

\section{다. 참여적 개발 기여도 평가}

수혜기관 직원 및 시역주민들은 Guji시역 $\mathrm{KOICA}$ 의 식수개발사업이 깨끗한 식수확보, 질병예방, 노동럭 경감에 크게 기여하고 있으며 지역사회발전에 대한 중 요성을 인식하고 있다. 그리고 수혜지역 주민의 식수 급수시설의 운영 및 보호를 위한 사치위원회 결성과 운영 및 의견제시, 수혜기관인 지방정부의 행정적 지 원 및 유사사업 계획 등 본 사입에 대한 관심이 크며 참 여의지가 강한 것으로 보인다.

\section{IV. 교훈 및 사후관리 필요사항}

\section{1. 교훈}

성공확률이 낮고 현장 사업수행여건이 열악한 지역을 대상으로 사업을 수행할 경우, 성공확률이 인빈적으로 $30 \%$ 이내로 매우 낮기 때문에 사전조사 및 검토가 충 분히 이루어진 이후에 사업대상시역과 수행방법을 결 정해야한다. 그리고 현지여건과 사정에 밝은 지역정부 에 사업을 위탁하여 수행하면 사업의 성공획률을 높일 수 있으며, 지역정부의 위탁을 통한 사업수행은 수혜 기관의 문제해결능력을 향상시키는(Capacity Building) 효과를 부가적으로 기대할 수 있다. 또한 사 업계획 수립시에 예상되는 리스크(강우, 분쟁, 물자부
족 등)를 충분히 분석하여 대응방안을 반영함으로서 사업수행을 원활히 추진할 수 있다.

\section{2. 사후관리 필요 사항}

지역주민 및 지방정부 수자원관리 담당자에 의하면 시 간의 경과에 따라 양수량이 시속적으로 감소되고 있다 고 한다. 이는 강수량의 부족에 따른, 낫은 지하수 함 양과 지하수 힘양 대비 과도한 양수에 기인하는 것으 로 판단된다. 따라서 양수강도, 앙수시간, 지하수위 강 하의 상관관계를 파악하고 적정 양수량을 산출하여 시 설관리자에 제공함으로서 개발된 지하수관정 활용의 지속성을 확보할 수 있을 것이다. 그리고 주민의견 청 취과정에서 기뭄에 의한 지역경제의 악화로 디젤언료 와 소모성 부품조달에 대한 경제적 어려엄이 제기되었 으녀, 단기간 지원은 가능하다고 판단되나 제공된 기 자재와 시설에 대한 수혜주민의 자치적 운용측면에서 주민 스스루 문제를 해견할 수 있도록 유도하는 것이 바람직하다고 판단된다.

\section{$\mathrm{V}$. 제안사항 및 건의}

\section{1. 사업수행의 효율성 제고}

사업대상 후보 지역의 지진, 강수량 등 자연특성은 지 하수기발의 승패를 좌우하는 가장 큰 요인이며, 사회 안정도, 기자재 수급현황, 수원국의 행정지원 등 사회 경제적 여건은 사업수행의 용이성과 호율성을 좌우한 다. 따라서 사업수행 여건과 사업호과 등을 충분히 고 
려하여 시업지역을 확정하고 세부계획을 수립함으로 서 사업의 성공가능성을 높일 수 있다. 특히 동아프리 카 시역은 사회기반시설이 열악하고 중족분쟁 등 사회 불안 요인이 상존하는 지역이므로, 사업형성을 위한 사전조사 시에 자연재해, 사회혼란 등 사업수행과정에 서 발생될 개연성이 있는 리스크를 충분히 검토하여 사업계획에 반형하면 사업수행과 목표달성이 보다 원 활히 이루어질 것으로 판단된다.

\section{2. 수원국의 수자원개발 능력배양 (Capacity Building)}

식수난이 심각한 동아프리카는 지역특성상 지하수개 발 성공확률과 지하수게발 관련 기술 수준이 낮은 지 역으로 자체기술력으로 지하수개발을 통한 식수공급 이 내우 어려운 실정이다. 따라서 사업수행과정에서 기술전수를 병행함으로서 향후 수원국의 식수문제 해 결능력을 배양시킨 필요성이 크다. 그리고 수원국은 지하수 양수 및 공급시설의 유지관리 경험이 일천하며 치원시설의 효용성이 난기간에 종료되는 경우가 빈번 히 빌생함에 따라 공여기자재 및 시설에 대한 유지 · 보수관련 기술의 전수를 통한 사업효과의 지속성 확보 방안이 필요하다.

또한 수원국의 기술수준에 따라 공동수행 혹은 수혜 기관에 위탁하여 신시하면 현지사정에 밝은 기관의
도움으로 사업을 효율적으로 수행할 수 있을 뿐만 아 니라 수원국의 기술능력 배양에 도움이 될 것으로 판 단된다.

\section{3. 향후 유사사업의 추진 필요성}

에티오피아를 비롯한 동아프리카 치역은 기후변화의 영향으로 가뭄과 이에 수반된 시수부족문제가 지속적 으로 발생할 개연성이 늪다. 또한 자체기술력의 부족 으로 스스로 문제를 해결할 능력이 없으며 외부의 지 원이 절실한 실정이다.

식수공급은 지표수와 지하수의 이옹으로 대별될 수 있 으며, 지표수는 고비용의 복잡한 정수과정이 필요하나 대용량 공급이 가능하여 도시의 식수공급에 많이 활용된다. 반면 지하수는 지표수에 비해 상내적으로 깨끗 하여 양수 후 별도의 징수과징을 거치지 읺고 식수공 급이 가능하나 대용량 확보가 어려워 농촌지역의 부락 단위의 식수공급에 많이 활용되고 있다.

지하수를 이용한 식수공급의 특성은 아프리카 농촌지 역의 인전한 식수공급에적합하다. 따라서 지하수개발 을 이용한 식수공급사업은 식수난이 극심한 농촌지역 의 식수공급에 효과성이 높으며 향후 시속적으로 추진 되어야 할 것으로 판단된다. 